\title{
PRODUÇÃO DE CARVÃo VEGETAL A PARTIR DA CARBONIZAÇÃO DE CAPIM ELEFANTE (Pennisetum purpureum Schum.)
}

\section{CHARCOAL PRODUCTION FROM CARBONIZATION OF ELEPHANT CAPIM (Pennisetum purpureum Schum.)}

\author{
S. M. M. VIEIRA ${ }^{1}$, F. S. VIEIRA ${ }^{2}$, C. C. CARVALHO ${ }^{3}$, L C. TRINDADE ${ }^{4}$, A. B. FRANÇA \\ ${ }^{1}$ Universidade Federal de São João Del Rei, Departamento de Engenharia Química, Brasil \\ ${ }^{2}$ Universidade Federal de São João Del Rei, Departamento de Engenharia Química, Brasil \\ ${ }^{3}$ Universidade Federal de São João Del Rei, Departamento de Engenharia Química, Brasil \\ ${ }^{4}$ Universidade Federal de São João Del Rei, Departamento de Engenharia Química, Brasil \\ ${ }^{5}$ Universidade Federal de São João Del Rei, Departamento de Engenharia Química, Brasil \\ E mail: sabrinamara89@yahoo.com.br
}

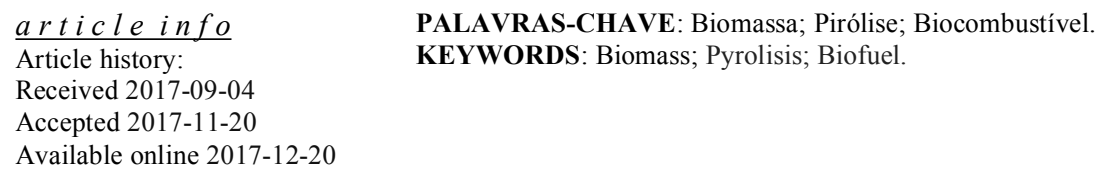

RESUMO: Pesquisadores e grandes empresas vêm buscando alternativas energéticas que possam diminuir a dependência e utilização de combustíveis de origem fóssil. Nesse sentindo, aponta-se o uso da biomassa como uma fonte renovável energética muito promissora e dentre elas destaca-se o capim elefante (Pennisetum purpureum Schum.). Seguindo essa vertente da tecnologia de biocombustiveis, neste trabalho foi realizada a transformação do capim elefante in natura até a obtenção do carvão, utilizando uma temperatura de carbonização de $450^{\circ} \mathrm{C}$. Posteriormente, realizaram-se caracterizações do material que permitiram o estudo de suas propriedades físico-químicas, tais como análise química imediata, poder calorífico e tensão de ruptura. Os resultados corroboram para a aplicação do carvão obtido como um combustivel promissor.

\begin{abstract}
Researchers and large companies have been looking for alternative energy sources that could reduce the dependence and use of fossil fuels. In this sense, the use of biomass as a very promising renewable energy source is pointed out, among them elephant grass (Pennisetum purpureum Schum.). Following this aspect of biofuel technology, in this work the transformation of the elephant grass in nature was carried out until the coal was obtained, using a carbonization temperature of $450^{\circ} \mathrm{C}$. Subsequently, characterizations of the material were made that allowed the study of its physicochemical properties, such as immediate chemical analysis, calorific value and rupture stress. The results corroborate the application of the obtained coal as a promising fuel.
\end{abstract}

\section{INTRODUÇÃO}

A evolução de processos industriais, da tecnologia e a melhoria na qualidade de vida da população estão diretamente associados à utilização de novos processos que demandam uma quantidade cada vez maior de energia (ANEEL, 2008). A maioria dos insumos energéticos utilizados na produção de energia em larga escala possuem reservas finitas, além 
de serem de origem fóssil e causarem grandes impactos ambientais, bem como na saúde da população.

Nesse sentindo, o interesse em novas alternativas energéticas sustentáveis tem crescido significativamente, como energias oriundas de fontes renováveis (CARVALHO, 2014). Dentre as fontes de energias sustentáveis, a biomassa se destaca em países tropicais, principalmente no Brasil, devido ao baixo custo e facilidade de ser encontrada (MAGALHÃES, 2014) .

O capim elefante é uma biomassa utilizada para alimentação de gado leiteiro, e tem sido estudada como uma fonte para geração de energia. A produção de carvão proveniente de biomassa de capim elefante pode ser uma alternativa ao coque, utilizado em indústrias siderúrgicas e tem se mostrado como um objeto de estudo promissor.

Portanto, o presente trabalho visou produzir carvão vegetal pelo processo de carbonização de capim elefante (Pennisetum purpureum Schum.) e avaliar as características principais do carvão produzido.

\section{MATERIAL E MÉTODO}

\subsection{Carvoejamento e Briquetagem}

Devido ao alto teor de umidade, o capim elefante foi previamente seco em estufa. A pirólise foi realizada para a produção de carvão em um forno tipo mufla. As condições de operação empregadas foram: Temperatura inicial de $25^{\circ} \mathrm{C}$; temperatura final de $450^{\circ} \mathrm{C}$ mantida por um intervalo de 120 min., e empregando uma rampa de aquecimento de $10^{\circ} \mathrm{C} \cdot \mathrm{min}^{-1}$

\subsection{Briquetagem}

Briquetes foram montados para avaliar ensaios de resistência à compressão. Os briquetes foram confeccionados em formato cilíndrico com diâmetro médio de $30 \mathrm{~mm}$ e altura média de $8 \mathrm{~mm}$. Os ensaios foram realizados pela Universidade Federal Fluminense, utilizando uma embutidora e aplicando uma força de $20 \mathrm{KN}$.

\section{3 Caracterização do carvão}

Análise química imediata: A análise imediata do carvão foi realizada obedecendo à norma NBR 8112. Através da realização dos ensaios obteve-se o teor de cinzas, voláteis e carbono fixo.

Resistência mecânica: $\mathrm{O}$ ensaio de resistência à compressão foi realizado pela Universidade Federal Fluminense (UFF).

Poder calorífico: Utilizou-se uma da Bomba Calorimétrica Parr modelo 3141, seguindo os passos da Norma ABNT NBR 8633. 


\section{RESULTADOS e DISCUSSÃO}

Os resultados de análise química imediata, resistência mecânica e poder calorífico estão exemplificados na Tabela 1.

Tabela 1- Valores de análise química imediata, resistência mecânica e poder calorífico do carvão de capim elefante.

\begin{tabular}{ll}
\hline Variáveis & Valor \\
\hline Teor de Cinzas & Análise Química Imediata \\
Teor de Voláteis & $13,82 \%$ \\
Teor de Carbono Fixo & $21,18 \%$ \\
\hline
\end{tabular}

\section{Resistência Mecânica}

Tensão de Ruptura

$16,21 \mathrm{kgf} . \mathrm{cm}^{-2}$

Poder Calorífico

Poder Calorífico Inferior

$5924,16 \mathrm{kcal} . \mathrm{Kg}^{-1}$

Fonte: Elaborado pelos Autores(2017).

Quintanilha (2012) em seu trabalho obteve a análise imediata de carvão de capim elefante cujos valores apresentados são: carbono fixo 43,1\%\%; Cinzas 19,4\% Matéria Volátil $37,5 \%$. Os resultados apresentados mostram valor aproximado para o teor de cinzas obtido, porém menor valor de carbono fixo e maior valor de material volátil. A partir de comparações feitas entre outros tipos de carvões produzidos por diferentes tipos de biomassa, percebe-se que para os resultados de análise química imediata existem valores diferenciados para cada um desses estudos. Infere-se que os resultados estão correlacionados as condições aplicadas na pirólise e principalmente, ao tipo de biomassa carbonizada, pois podem apresentar diferentes quantidades de fibras que interferem diretamente nas porcentagens de cinzas, voláteis e carbono fixo.

Mendes e colaboradores (1982) realizaram teste de compressão em carvão oriundo da carbonização da madeira de Eucalipto e obtiveram como tensão de ruptura do material o valor de $20,9 \mathrm{Kgf}$. $\mathrm{cm}^{-2}$, para temperatura de carbonização de $500^{\circ} \mathrm{C}$. O resultado está próximo àquele encontrado nesse trabalho para o carvão de capim elefante, cujo valor é 16, $21 \mathrm{Kgf}_{\mathrm{cm}}{ }^{-2}$. Nota-se que o valor encontrado é relativamente baixo para aplicações em processo industriais, porém a resistência mecânica pode ser aumentada empregando-se o uso de ligantes que favoreçam melhorias mecânicas, os quais deverão ser adicionados na etapa de briquetagem. 
$\mathrm{Na}$ literatura os valores de poder calorífico apresentados pelo carvão proveniente de eucalipto, situa-se em torno de $7000 \mathrm{kcal} . \mathrm{kg}^{-1}$, apresentando valor superior ao encontrado para o carvão de capim elefante. No entanto, mais uma vez podemos associar os resultados obtidos ao tipo de biomassa utilizada para a obtenção do carvão. Além dos fatores atribuídos a biomassa, valores aumentados de teores de cinzas e carbono fixo interferem no resultado dessa análise, os quais estão intimamente relacionados aos teores de fibras de cada matéria prima.

\section{CONCLUSÃO}

O carvão obteve resultados comparáveis aos valores usuais de carvões provenientes de outros tipos de biomassa geralmente utilizadas, como o eucalipto. O carvão pode ser destinado para diferentes utilizações, como churrascarias em processos siderúrgicos em conjunto ao coque, porém em ressalva à algumas limitações como o teor de cinzas e a resistência mecânica e demais aplicações de demanda energética. Melhorias podem ser realizadas para qualificar seu uso industrial.

\section{AGRADECIMENTOS}

À FAPEMIG pelo apoio financeiro concedido. À Universidade Federal Fluminense. Ao professor José Antônio da Silva pelas análises concedidas.

\section{REFERÊNCIAS}

ANEEL. Atlas de energia elétrica do Brasil. Agência Nacional de Energia Elétrica. 236 p. 3. ed. Brasília: ANEEL, 2008.

CARVAlHO, G. B. Caracterização da produção de biomassa de capim-elefante (Pennisetum purpureum, Schum.), cv. Cameroon, em função da adubação nitrogenada e irrigação em região semiárida. 2014. 179 f. Tese (Doutorado Ciências. Área de concentração: Irrigação e Drenagem). Piracicaba, 2014.

MAGAlhãeS, M. A. Produção Caracterização de Pellets de Capim elefante (Pennisetum purpureum Schum). 2014. 35f. Trabalho (Conclusão de cursoEngenharia Florestal)- Universidade Federal de Viçosa. Viçosa, 2014.

MENDES, M. G.; GOMES, P. A.; OLIVEIRA, J. B. Propriedades e Controle de Qualidade do Carvão Vegetal. Fundação Centro Tecnológico de Minas Gerais CETEC. Produção e utilização de carvão vegetal. 1982. [Série de Publicações Técnicas, 6:75-89].

QUINTANILlA, J. E. A.,Reatividade ao $\mathrm{CO}_{2}$ de Carvões Minerais de Biomassas e Coques. 2012. 18 f. Dissertação (Mestrado em Engenharia de Materiais e Processos Químicos e Metalúrgicos), Pontifícia Universidade Católica do Rio de Janeiro, Rio de Janeiro, 2012. 